DOI: $\underline{\text { https://doi.org/10.24867/06AM00Loncar }}$

\title{
ANALIZA TAČNOSTI KOORDINATNIH MERNIH SISTEMA PRI ODREĐIVANJU GREŠKE RAVNOSTI
}

\section{ACCURACY ANALYSIS OF COORDINATE MEASURING SYSTEMS TO DETERMINE THE FLATNESS ERROR}

\author{
Milan Lončar, Branko Štrbac, Fakultet tehničkih nauka, Novi Sad
}

\begin{abstract}
Oblast - MAŠINSTVO
Kratak sadržaj - Razvojem proizvodnje ka složenim radnim predmetima sa uskim tolerancijama izrade dovelo je koordinatne merne sisteme (KMS) na lidersku poziciju u procesima verifikacije. Postoji niz razlicitih KMS koje se danas koriste a karakterišse ih način uzorkovanja, tačnost, brzina, fleksibilnost. Mnoge KMS nemaju utvrđene procedure za proveru tačnosti. Ova rad je imao za cilj da utvrdi tačnost različit KMS na primeru merenja etalona ravnosti sa poznatim kalibracionim vrednostima. Rezultati su pokazali visoke performanse koordinatnih mernih mašina za obe vrste senzora a loše performanse za industrijski $C T$.
\end{abstract}

Ključne reči: Koordinatni merni sistemi, greška ravnosti, rotacija kroz jednu tačku

\begin{abstract}
With the development of manufacturing towards complex workpieces with narrow tolerances, it has brought coordinate measurement systems (CMS) to a leading position in the verification processes. There are a number of different CMS used today that are characterized by sampling mode, accuracy, speed, flexibility. Many CMS do not have established procedures for verifying accuracy. This paper aimed to determine the accuracy of different CMS on the example of measuring the standards of flatness with known calibration values. The results showed high performance coordinate measuring machines for both probe and poor performance for industrial CT.
\end{abstract}

Keywords: Coordinaty measurement systems, flatness error, Bundle of plains through one point

\section{UVOD}

Sa početnim razvojem koordinatnih mernih sistema (KMS) 1970-tih, trodimenzionalna (3D) metrologija je postala osnova $\mathrm{u}$ industiji. Koordinatni merni sistemi su postigli široku popularnost kao fleksibilno rešenje $u$ bezbroj mernih potreba. $\mathrm{Sa}$ porastom korišćenja geometrijskog dimenzionisanja i tolerisanja, KMS su dominantne mašine dimenzionalnih metrologa. KMS, sa pogodnom opremom, se mogu koristiti za merenje praktično bilo kog parametra koji je označen na tehničkoj dokumentaciji, pošto u osnovi uočavaju jedino koordinate tačaka koje se nalaze na površini radnog predmeta [1].

\section{NAPOMENA:}

Ovaj rad proistekao je iz master rada čiji mentor je bio doc. dr Branko Štrbac.
Tačnost u detektovanju položaja mernih tačaka zavisi pre svega od tipa koordinatnog mernog sistema (hadverska struktura), sistema uzorkovanja (merni senzor), načina uzorkovanja tačaka, itd. Koordinatni merni sistemi se mogu podeliti u dve grupe: sistemi koji uzorkuju tačke na diskretan način i sistemi koji prikupljaju tačke u vidu skeniranja. Preciznost i tačnost ovih različitih mernih sistema se oslikava u ispravnosti detektovanja koordinata tačaka. Nakon toga, u nezavisnim softverskim analizama, na bazi izmerenih tačaka, procenjuju se karakteristike kvaliteta proizvoda. Industrija zajedno sa metrološkim institutima razvila procedure za testiranje koje omogućavaju proizvođačima ovih metroloških sistema kao i krajnjim korisnicima da procene performanse različitih tipova KMS. Specifične procedure prihvatanja i reverifikacije su uspostavljene u mnogim nacionalnim i međunarodnim smernicama. Međutim, uspostavljanje sledljivosti na različitim KMS moguće je ostvariti samo korišćenjem dobro poznatih metoda supstitucije zasnovane na kalibrisanim radnim predmetima i korišćenjem naprednih virtualnih mernih mašina [2].

U ovom radu analizirana je greška ravnosti merena na različitim koordinatnim mernim sistemima a procena greške je izvršena $u$ istom programskom sistemu. Sledljivost je uspostavljena korišćenjem etalona ravnosti - plan paralelne merke.

\section{PREDMET ISTRAŽIVANJA}

Kako je već rečeno, princip rada većine koordinatnih mernih sistema se odvija u dve nezavisne faze: fizičko uzorkovanje podatake tačaka sa realne geometrije radnog predmeta i nezavisna softvera analiza uzorkovanih podataka [3]. Druga faza je kod svih KMS identična tj. koriste se kompatibilni softveri za određeni KMS ili se koriste univerzali softveri ako su izvedeni podaci o realnoj geometriji radnog predmeta čitljivi. U prvoj faze su prisutne razlike između određenih KMS. Naime, tačnost određenog mernog sistema se ispoljava u tačnosti uzorkovanja koordinate uzorkovane tačke. Na tačnost uzorkovane tačke utiče mnogo faktora, pre svega tu je 21 geometrijska greška ako se radi o konvencionalnim KMM i greške senzora. Za ocenu tačnosti uzorkovane tačke na KMM vrši se merenje male precizne sfere u 49 tačaka i (najmanji kvadrati) najbolje fitovana sfera se izračunava [4]. Radijalni reziduali svake merne tačke od best fit radijusa su određeni, i njihova standardna devijacija se koristi za pojedinačni parametar da okarakteriše nesigurnost tačke KMM. Iako je ova procedura 
sprovedena na maloj sferi, može se zamisliti da se njegov prečnik smanjuje do nule, i rezultat 49 merenja iste (fizičke) tačke, sa standardnom devijacijom ovih 49 vrednosti dovodi do karakteristika nesigurnosti tačke. Prednost ove metode jeste da mnogi KMM korisnici znaju vrednost za tačka po tačka testa performanse senzora i stoga i lako mogu izvršiti test za procenu ove vrednosti. Ovo pokazuje da svaka izmerena tačka ima verovatnosti opseg koji se naziva merna nesigurnost uzorkovane tačke i na ovaj način se samo definiše netačnost senzora. Međutim, uzorkovana tačka u drugom položaju u KMM zampemini će imati drugačiji verovatnosti opseg pojavljivanja jer geometrijske greške nisu jednake duž mernog prostora mašine.

Stoga, ne može se uvesti pojednostavljenje da je greška tačke uzorkovanja ravnomerna u raspoloživom mernom prostoru KMM. Isto tako, pri oceni supstitutivne geometrije, potrebno je analizirati određeni skup tačaka koja svaka ima različit stepen tačnosti. Ovde je jako bitno i koja matematička metoda za procenu supstitutivne geometrije se koristi. Posebno je ovo se interesantno ispitati ako se procenjuje neka geometrijska karakteristika kao što je na primer greške oblika određenog geometrijskog primitiva.

Isto tumačenje se može izvesti za ostale KMS stim da postoji mnogo više faktora koji će uticati na tačnost uzorkovanja koordinate tačke sa radnog predmeta.

Ovaj rad ima za cilj da analizira tačnost različitih KMS tako što se meri etalon ravnosti (plan paralelna granična merka) poznatih kalibracionih vrednosti. Izlaz iz svakog analiziranog KMS je skup koordinata tačaka $(x, y, z)$ koji se analiziraju u nezavisnoj softverskoj analizi. Procenjuje se greška ravnosti u nekomercionalnom softveru koji se bazira na metodi - Rotacija kroz jednu tačku [5].

Koordinate uzorkovanih tačaka će sadržati sve nesavršenosti tog mernog sistema i procenjena greška merenja će se porediti sa kalibrisanom vrednošću greške ravnosti i na taj način će se sprovesti uporedna analiza tačnosti različitih koordinatnih mernih sistema za merni zadatak greške ravnosti

\subsection{Predmet merenja}

U cilju procene tačnosti različitih koordinatnih mernih sistema merena je plan paralelna merka koja se može smatrati etalonom ravnosti. Plan-paralelne merke izrađuju se od optičkog stakla velike tačnosti. U ovoj studiji slučaja mereno je plan paralelna granična merka prikazano na slici 1 čije su karakteristike date u tabeli 1 . Kalibracione vrednosti su dobijene koristeći laserski interferometar.

Tabela 1. Podaci o predmetu merenja

\begin{tabular}{|lc|}
\multicolumn{1}{|c|}{ Proizvođač } & Mitutoyo \\
\hline Debljina & $t=12 \mathrm{~mm}$ \\
\hline Prečnik & $d=30 \mathrm{~mm}$ \\
\hline $\begin{array}{l}\text { Greška ravnosi iz kalibracionog } \\
\text { setifikata }\end{array}$ & $\delta=0,03 \times 10^{-3}$ \\
\hline Nesigurnost kalibracije & $\mathrm{mm}$ \\
\hline
\end{tabular}

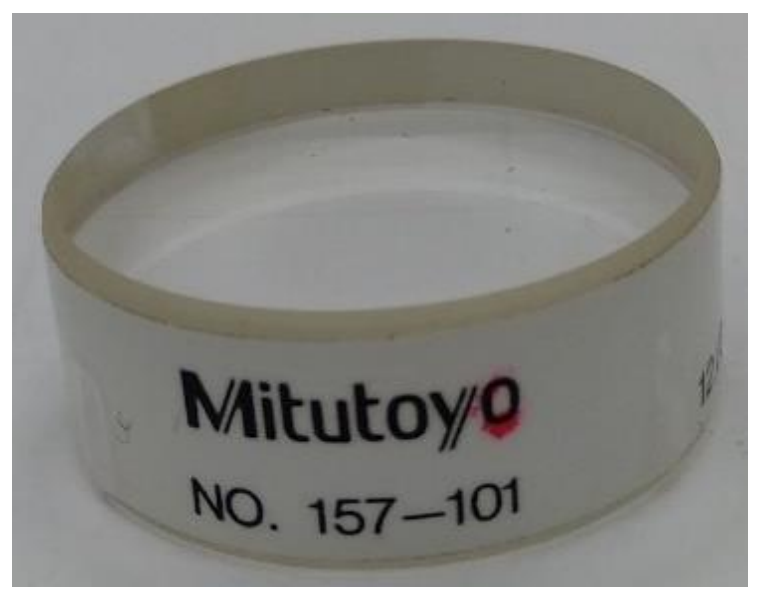

Slika 1. Predmet merenja

\subsection{Ocena greške ravnosti}

Geometrijski element ravan je jedan od osnovnih geometrijskih primitiva koji je osnova mnogih mehaničkih proizvoda za postizanje namenjene funkcionalnosti. Ravnost površine je stanje u kom svi elementi površine pripadaju jednoj ravni što odgovara idealnoj ravni. Procena greške ravnosti se obično vrši uz pomoć računara zasnovano na algoritmima koji bi trebalo da budu robusni, efikasni i na bazi proverenih matematičkih principa. Takođe, ovi programi bi trebalo da slede smernice postavljene $u$ standardima. ANSI standard dimenzionisanja i tolerisanja Y14.5 definiše, procenjuje tolerancije oblika na komponentama u odnosu na idealne geometrijske oblika. Za evoluaciju oblika, ISO standardi navode da idealni geometrijski elementi moraju biti uspostavljeni iz stvarnog merenja, tako da ostupanje između idealnih i stvarnih geometrisjkih elemenata je najmanja moguća vrednost. Podaci dobijeni pomoću KMM su analizirani koristeći tehnike zasnovane na fitovanju. Dve najčešće tehnike fitovanja su metoda najmanjih kvadrata (LS) i metod minimalne zone (MZ) koji spada u ekstremne algoritme fitovanja. LS je superiorniji u odnosu na MZ sa stanovišta jednostavnosti i vremena računanja. LS generalno procenjuje grešku oblika i samim tim može dovesti do odbacivanja dobrih delova gde $\mathrm{MZ}$ teži da loše proceni grešku oblika i veoma je osetljiv na pikove koji mogu, koje ako se ne primete, dovesti do loših rezultata. LS ne prati pažljivo standarde i ne može da garantuje da je rešenje minimalne zone specifirano u standardu. U ovom master radu za procenu greške ravnosti korišćena je metoda rotacija kroz jednu tačku bazirana na MZ metodologiji i razvijena je na Fakultetu tehničkih nauka [5].

Metoda rotacija kroz jednu tačku se bazira na osobinama referentne ravni koja predstavlja osnovu za procenu greške ravnosti. Iz analitičke geometrije je poznato da su tri koordinate normalnog vektora ravni jedini parametri koji utiču na vrednost greške ravnosti. Pritom položaj stvarne ravni nije značajan iz razloga što njegove ortogonalne transformacije ne utiču na ravnost. To znači da $\mathrm{u}$ jednačini referentne ravni date preko formule (1)

$$
z=-\frac{A x+B y+D}{C z}
$$

A, B i C predstavljaju koordinate vektora normale ravni a D je konstanta koja je definisana sa položajem ravni. Parametar D je beznačajan i nema uticaja na procenu 
greške ravnosti. Ovo navodi na zaključaj da ako se uzme bilo koja ravan sa specifičnim vektorom normale definisanim preko parametra A, B i C rezultat procene greške ravnosti će biti isti. Drugim rečima, položaj ravni određen preko rotacije vektora normale i činjenice da tačka A pripada ravni, definisaće vrednost parametra D koji se koristi za izračunavanje ortogonalnih rastojana od generisanih ravni i procenu greške ravnosti. Referentna ravan može biti smeštena u bilo koji tačku koja pripada setu uzorkovanih tačaka na koordinatnom mernom sistemu. Položaj ravni u prostoru određem uglovima $\xi$ i $\theta$ i parametri referentne jednačine $\mathrm{A}, \mathrm{B}$ i C se određuju preko iterativnog postupka. Naime, ravan rotira oko slučajno izabranih tačaka u prostoru i miimalno rastojanje između uzorkovanih tačaka se određuje prema definiciji tolerancijske zone ravnosti. Koraci rotacije oko $\mathrm{x}$ i z ose su definisani kao odnos maksimalnih uglova $\xi$ and $\theta$ i odgovarajućih brojeva definisanih koraka. Broj koraka je potrebno definisati pre softverskog proračuna. Svaki put kada referentna ravan zauzme određeni položaj u prostoru definisan uglovima $\xi$ and $\theta$ softver će registrovati parametre vektora normale referentne ravni i grešku ravnosti. Postupak će se ponavljati za sve definisane korake i softver će registrovani onaj vector normale referentne ravni čiji položaj određuje najmanju grešku ravnosti za posmatrani skup uzorkovanih tačaka.

\section{EKSPERIMENTALNA ISTRAŽIVANJA}

Plan - paralelna merka je merena na nekoliko različitih koordinatnih mernih sistema i različitih senzora. Operateri su uzimali slične strategije merenje na taj način uzorkovane tačke obuhvate celu ispitivanu površinu (kod nekih mernih instrumenata nije bilo izvodljivo primeniti sličnu strategiju merenja). Nakon uzorkovanja, podaci uzorkovanih tačaka ( $x, y, z$ koordinate) $\mathrm{u}$ izvezene $\mathrm{u}$ programiski sistem koji je izgrađen na bazi MZ rešenja - rotacija kroz jednu tačku. Na ovaj način su isključe eventualne različitosti između softvera koji podržavaju rad određeneg KMS i u rezultatu merenja su sadržane netačnosti koji potiču od hadvera određenog KMS. Na slici 3 su prikazani KMS i merni senzori, kao i njihove karakteristike, koji su se koristili u ovom istraživanju. Više detalja o analizi greške ravnosti, različitim mernim instrumentima, proceni njihove tačnosti kao i vrednosti koordinata uzorkovanih tačaka može se pronaći u master radu iz kog je proistekao ovaj rad.

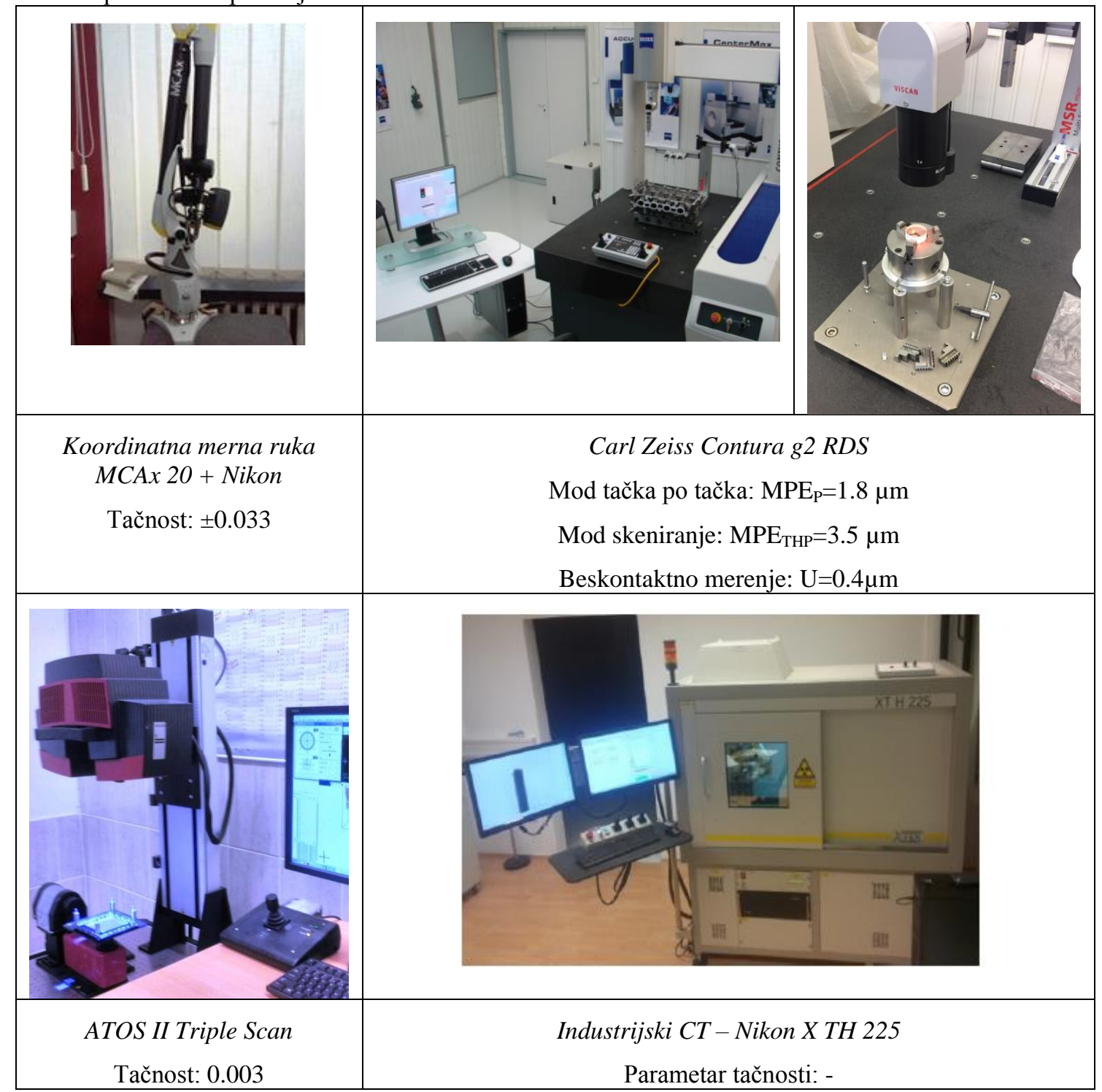

Slika 1. Koordinatni merni sistemi korišćeni u studiji 
$\mathrm{Na}$ slici 4. data je uporedna analiza grešaka ravnosti procenjenih na različitim koordinatnim mernim sistemima. Sa slike se mogu uočiti visoke performanse KMM pri merenju i sa kontaktnim i beskontaktnim senzorom što pokazuje da na grešku merenja više utiču geometrijske greške mašine od samih grešaka senzora. Ovo što je potvrdio ovaj eksperiment je to da u modu tačka po tačka merni sistem ima bolje performanse u rado od moda skeniranje. Skener ATOS je pokazao veoma dobre performanse i njegovi rezultati su neznatno manji od merenja na KMM. Veoma loše rezultate su pokazali merna ruka i industrijski CT. Merna ruka koja je korišćena u ovom radu spada nema visoke metrološke performanse dok se od industrijskog CT-a, čije merenje ima najveću grešku, očekivali mnogo bolji rezultati. Međutim, treba još jednom pomenuti da je predmet merenja bio proziran što predstavlja velik problem da beskontakne metode merenja među kojima je i CT.

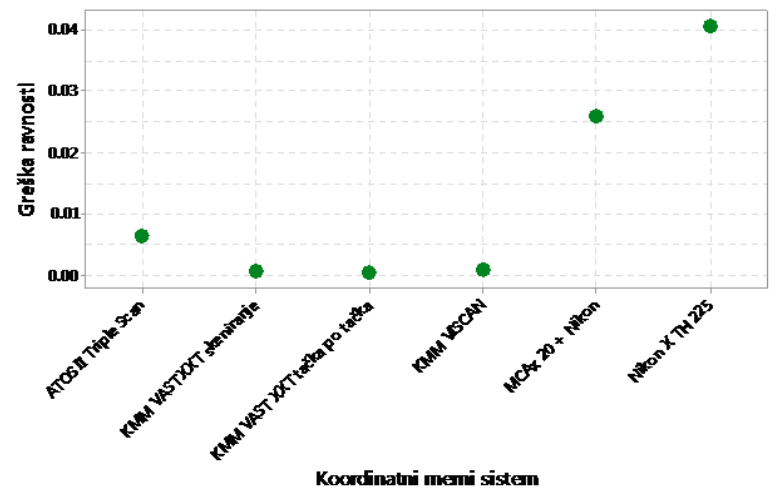

Slika 4. Analiza tačnosti različitih KMM pri merenju etalona ravnosti

\section{ZAKLJUČAK}

Provera usaglašenosti dimenzionalnih i geometrijskih tolerancija sa specifikacijskim zahtevima skoro da je nezamisliva bez upotrebe nekoh tipa koordinatnog mernog sistema. To su merni instrumenti koji prikupljaju podatke o realnog geometriji preko određenog tipa mernog senzora. Danas postoji mnošto različitih tipova KMS i mernih senzora. Opšta podela je na kontaktne i beskontakne merne sisteme, gde određeni sistem, uz odgovarajuće senzore, može biti i jedno i drugu. Uglavnom su kontaktni sistemi tačniji ali im treba mnogo više vremena da uzorkuju (digitalizuju) predmet merenja dok beskontaktni mogu sa veoma kratak vremenski period da prikume i do nekojiko hiljada tačaka.

Ovaj rad se bavio tačnosti nekoliko različitih KMS pri merenju etalona ravnosti - plan paralelna merka. Etalon je meren sličnom strategijom, koliko je to bilo moguće, a greška merenja je procenjena na isto nekomercionalnom softveru. Eksperimentalna istraživanja su pokazala visok stepen tačnosti KMM pri korišćenju oba moda kontaktnog senzora kao i beskontaktnog senzora. Takođe, utvrčena je velika netačnost najsavremenijeg KMS - industrijskog CT-a.
Imajući u vidu da je radni predmet proziran ova činjenica je dosta nepogodna za upotrenu bilo koje vrste beskontaktnog senzora. Iz tog razloga, istraživanja bi trebalo proširiti i na druge referentne predmete kao što su etalon prstenovi, granične merke, referenti konusi, ball bar, ploča sa otvorima, itd.

\section{LITERATURA}

[1] B. Štrbac, V. Radlovački, V. Spasić-Jokić, M. Delić, M. Hadžistević, ,The difference between GUM and ISO/TC 15530-3 method to evaluate the measurement uncertainty of flatness by a CMM“ MAPAN, Vol. 32, pp. 251-257, 2017.

[2] B. Acko, M. McCarthy, F. Haertig, B. Buchmeister, „Standards for testing freeform measurement capability of optical and tactile coordinate measuring machines", Measurement Science and Technology, , Vol 23, 2012.

[3] X-L. Wen, X-C. Zhu, B-Y. Zhao, D-X. Wang, F-L Wang, Flatness error evoluation and verification based on new generation geometrical product specification (GPS), Vol. 36, pp. 70-76, 2012.

[4] S. D., Phillips, B. Borchardt, W.T. Estler, and J. Buttress, The estimation of measurement uncertainty of small circular features measured by coordinate measuring machine, Precision Engineering, Vol. 22(3), pp. 87-97, 1998.

[5] V. Radlovački, M. Hadžistević, B. Štrbac, M. Delić, M, B. Kamberović, ,Evaluating minimum zone flatness error using new method - bundle of plains through one point", Precision Engineering, Vol. 43, pp. 554-562, 2016.

\section{Kratka biografija:}

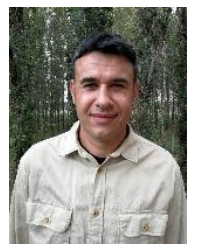

Milan Lončar rođen je u Novom Sadu 1974. god. Master rad na Fakultetu tehničkih nauka iz oblasti Proizvodno mašinstvo odbranio je 2019.god.

kontakt: milan.loncar@unimet.rs

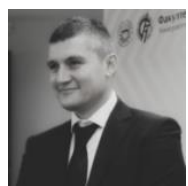

Dr Branko Štrbac rođen je u Novom Sadu 1983. Doktorirao je na Fakultetu tehničkih nauka 2017. god. i od tada je u zvanju docent. Oblast interesovanja su proizvodna metrologija. 